\title{
Particle Size Distribution Based Occurrence Features of Organic Components in Printing and Dyeing Wastewater Under a Treatment Process
}

\author{
Yuan $\mathrm{Li}^{1}$, Jie $\mathrm{Liu}^{2}$, Yibiao $\mathrm{Yu}^{1}$, Hao $\mathrm{Zhu}^{3}$, Zheng Shen ${ }^{1,2, *}$, and Yalei Zhang ${ }^{1,2}$ \\ ${ }^{1}$ National Engineering Research Center of Protected Agriculture, Tongji University, Shanghai 200092, China \\ ${ }^{2}$ State Key Laboratory of Pollution Control and Resource Reuse, Tongji University, Shanghai 200092, China \\ ${ }^{3}$ China Rural Technology Development Center, Beijing 100032, China
}

\begin{abstract}
A more detailed occurrence features of organic matters in the printing and dyeing wastewater, based on its particle size distribution (PSD) and along with a wastewater treatment process, was conducted to provide a support for advanced treatment. Results suggested that, (1) In the dyeing wastewater, the occurrence characteristic of COD was: soluble>supra colloidal $>$ colloidal $>$ settleable; However, for protein, the supra colloidal was dominant, followed by the soluble. The feature of the polysaccharide was consistent with COD's. In the wastewater, $29.66 \%$ of COD could be attributed to proteins and $3.45 \%$ of the COD could be attributed to polysaccharides. (2) The relationship among the forms of COD in the primary sedimentation tank, aerobic tank, secondary sedimentation tank, and reverse osmosis-treated concentrated effluent was consistent, that was: soluble>colloidal $>$ supra colloidal $>$ settleable. (3) In the primary sedimentation tank, the settleable COD was almost completely removed; In the aerobic tank, the residual super colloidal COD was not much; After MBR-RO treatment, the COD in the reverse osmosis concentrated water was almost dissolved and only a little presented in other forms.
\end{abstract}

\section{Introduction}

Traditionally, a large amount of water consumption and pollution discharge is associated with China's printing and dyeing industry[1]. According to the statistics, there are hundreds of thousands of companies engaged in the textile industry and related work and the output of dyes and pigments being consumed industrially is over $7 \times 10^{5}$ tons annually[2]. Printing and dyeing wastewater has the characteristics of large volume, deep color, large alkalinity, high content of organic pollutants and complex composition[3, 4], and it is one of the industrial wastewaters that are difficult to be treated. With the application of PVA slurry, rayon saponification and a large number of new auxiliaries, a large amount of refractory organic matter enters the wastewater. If such untreated printing and dyeing wastewater is directly discharged into natural water bodies, the pollutants in the wastewater will compete with aquatic organisms for dissolved oxygen in the water, destroy the ecological balance of the water environment and affect the entire ecosystem. At present, domestic and foreign researchers mainly deal with printing and dyeing wastewater by coagulation sedimentation method, adsorption method, membrane separation technology, advanced oxidation method, electrochemical method and biological treatment method[5, 6]. As reverse osmosis(RO) process[7] can effectively barrier various ions and large contaminants, it has also been widely applied in printing and dyeing wastewater treatment. The development trend of advanced treatment of printing and dyeing wastewater is mainly in the following aspects: clean production, quality treatment and reuse, optimized combination and integration of processes.

Even $0.45 \mu \mathrm{m}$ is often used to divide particulate and soluble components[8], partitioning pollutant fraction with a more detailed differentiation standard has gradually attracted wide attention. Several researchers discussed the particle size distribution(PSD) of water contaminations in municipal wastewater (both rural areas and urban areas) $[9,10]$. Also some explored related laws of industrial wastewater, such as textile wastewater[11], petrochemical wastewater[12] and tannery wastewater[8]. However, there has limited studies in printing and dyeing wastewater where PSD has been analyzed.

The aim of this study is to introduce an additional insight of printing and dyeing wastewater and provide data support for advanced treatment. In this study, occurrence characteristics of PSD based COD in printing and dyeing wastewater was invested. The variation of PSD based COD changing with different structures was explored. Moreover, the occurrence characteristics of proteins and polysaccharides in printing and dyeing wastewater were studied.

\footnotetext{
* Corresponding author:78shenzheng@tongji.edu.cn
} 


\section{Materials and methods}

\subsection{Sampling}

A printing and dyeing company in Shaoxing, Zhejiang Province, was engaged in a variety of printing and dyeing processes, including cotton textile printing and dyeing, wool textile dyeing and finishing, and printing. Wastewater from this company was treated by a purification process as shown in Fig. 1. The COD value of the raw water sample collected, the primary settling

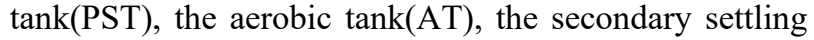
$\operatorname{tank}(\mathrm{SST})$ and reverse osmosis(RO) external drainage was $2000-3000 \mathrm{mg} / \mathrm{L}, 700-900 \mathrm{mg} / \mathrm{L}, 200-400 \mathrm{mg} / \mathrm{L}, 250$ $400 \mathrm{mg} / \mathrm{L}$ and $300-500 \mathrm{mg} / \mathrm{L}$, respectively. The conductivity of the collected water samples was around $2600 \mu \mathrm{s} / \mathrm{cm}$. The company's wastewater treatment capacity was about 3600 tons/day, the reuse rate was $16.67 \%$, and the amount of water discharged was 30003200 tons/day. The effluent water with a maximum COD limit of $500 \mathrm{mg} / \mathrm{L}$, which included concentrated water treated by RO and effluent treated by an SST, was discharged to a centralized treatment sewage station in an industrial park.

\subsection{Separation}

In this paper, the water sample was divided into four parts: particle state $(>100 \mu \mathrm{m})$, super colloid state $(100-1 \mu \mathrm{m})$, colloidal state $(1-0.22 \mu \mathrm{m})$ and dissolved state $(<0.22 \mu \mathrm{m})[13]$.

The sample collected sequentially passed through a $100 \mu \mathrm{m}$ membrane of nylon material, a $1 \mu \mathrm{m}$ membrane of mixed cellulose ester material and a $0.22 \mu \mathrm{m}$ microporous membrane of mixed cellulose ester material.

Before the operation, filter devices and membrane discs were rinsed by running water for 3 times, then rinsed by $70 \%$ ethanol for several times, and finally rinsed by distilled water for several times until there was no residual alcohol. Existence of residual distilled water in the device could bring error to the experimental concentration, thus before filtration, filter device was oven-dried and then kept undisturbed waiting for temperature recovery.

\subsection{Chemical analysis}

All conventional analyses were performed in duplicates and done according to the Standard Methods[14]. Protein measurement was conducted based on a modified Lowry method[13, 15].

Protein and polysaccharide were converted into values with units of COD to calculate their proportions existing in organic matters. The conversion coefficient of the protein and polysaccharide were $1.50 \mathrm{~g} \mathrm{COD} /(\mathrm{g}$ protein) and $1.07 \mathrm{~g} \mathrm{COD} /(\mathrm{g}$ polysaccharide), respectively[16].

The concentration of organic components measured for each wastewater samples was recorded as $\mathrm{N}_{\text {raw. }}$. The concentration of wastewater flow through the $100 \mu \mathrm{m}$, the $1 \mu \mathrm{m}$, the $0.22 \mu \mathrm{m}$ were recorded as $\mathrm{N}_{100}, \mathrm{~N}_{1}$ and $\mathrm{N}_{0.22}$, respectively. Subsequently, the concentration of organic components existing in the four size fractions could be calculated as Table 1 .

Table 1. Calculation formula of the concentration of organic components existing in the particle, super colloid, colloidal and dissolved fractions.

\begin{tabular}{|c|c|}
\hline Occurrence Form & Calculation Formula \\
\hline Particle State & $\mathrm{N}_{\text {raw }}-\mathrm{N}_{100}$ \\
\hline Super Colloid State & $\mathrm{N}_{100}-\mathrm{N}_{1}$ \\
\hline Colloidal State & $\mathrm{N}_{1}-\mathrm{N}_{0.22}$ \\
\hline Dissolved State & $\mathrm{N}_{0.22}$ \\
\hline
\end{tabular}

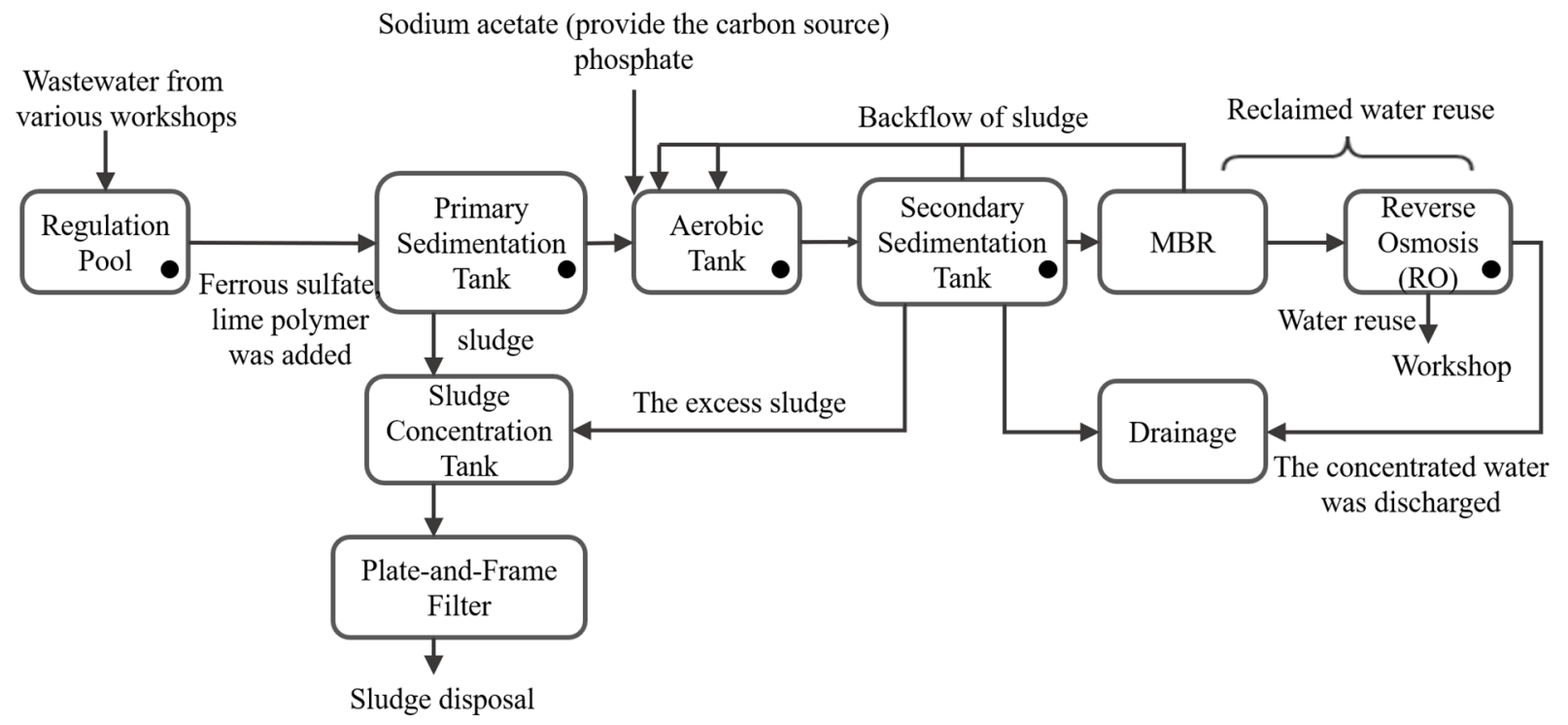

Fig. 1. The craft of the wastewater treatment applicated in a printing and dyeing company in Shaoxing, Zhejiang Province, China. The solid points denote the sampling points. 


\section{Results and discussion}

\subsection{COD occurrence characteristics in the raw wastewater}

COD occurrence characteristics in the raw wastewater could be revealed in Fig.2. It can be seen in Fig.2 that, $64.19 \%$ of the COD existed in the dissolved form. Secondly, there was also $23.08 \%$ COD exists in the super colloid form and $11.33 \%$ in the colloidal state. The particulate state was determined as the minimum portion with an only $1.4 \%$ content. In summary, it can be concluded that the majority of COD in the raw printing and dyeing wastewater was dissolved, followed by the super-colloidal state and subsequently in the form of colloidal state. Of course, the occurrence of COD in the printing and dyeing wastewater organic matter is related to the purification process used and kinds of dyes.

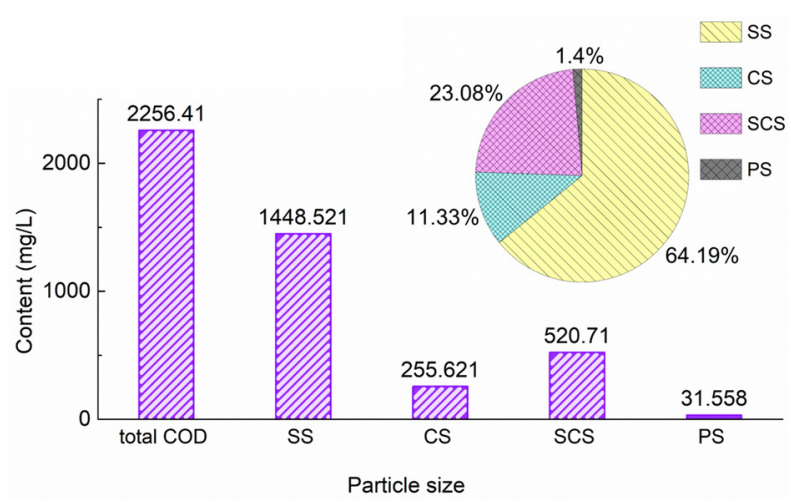

Fig. 2. COD occurrence characteristics in the raw wastewater. The SS, CS, SCS and PS presenting the soluble state, colloidal state, super colloid state and particulate state, respectively.

\subsection{Occurrence characteristics of other organic components in the raw wastewater}

PSD-based protein and polysaccharide occurrence characteristics and the occurrence characteristics of total organic components existing in the raw printing and dyeing wastewater are pictured in Fig.3. It can be seen from the histogram of Fig. 3 that the super colloidal protein accounted for the highest proportion of $53.94 \%$. Secondly, the dissolved protein also had an important position and accounted for $36.85 \%$ proportion. Protein in the form of particles was the least(only $1.41 \%$ ). It can also be seen from the histogram of Fig. 3 that in the raw water, the proportion of dissolved polysaccharides $(66.07 \%)$ was the highest, followed by the form of super colloids(16.62\%). Polysaccharides in the form of particles was the least(only 5.77\%). Comparing the information revealed from Fig.2 and Fig.3, it can be clearly seen that the distribution characteristic of the COD and its two organic components in wastewater did not necessarily follow the same rule. The dissolved state was dominant for COD and polysaccharide. While for protein, the super colloid was accepted as the dominant portion.

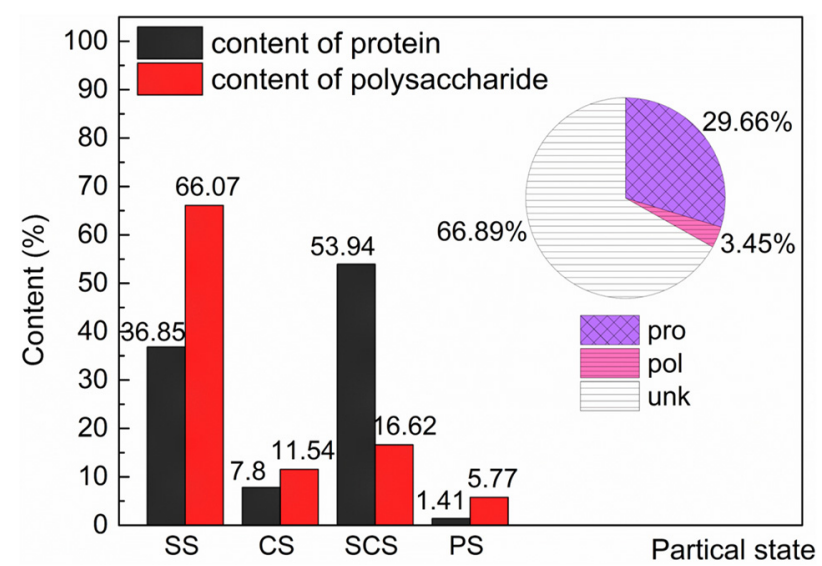

Fig. 3. The histogram representing PSD-based protein and polysaccharide occurrence characteristics in the raw printing and dyeing wastewater. The pie chart representing the occurrence characteristics of total organic components existing in the raw printing and dyeing wastewater. The SS, CS, SCS, PS, pro, pol and unk indicating the soluble state, colloidal state, super colloid state, particulate state, protein, polysaccharide and unknown substance, respectively.

The measured protein and polysaccharide in the raw water were changed to the COD equivalent value according to the conversion coefficient in Section 2.3, and the occurrence ratio of the organic components in the raw water was counted by the Origin. The result is shown in the pie chart of Fig.3. As pictured, COD in raw water consisted of $29.66 \%$ protein, $3.45 \%$ polysaccharide and $66.89 \%$ unknown substance. Analysed from the printing and dyeing process, $66.89 \%$ of the unknown substances may contain organic substances such as surfactants[17] and PVA slurries[18].

\subsection{PSD based COD occurrence characteristics of samples from the primary sedimentation tank, the aerobic pool, the secondary sedimentation tank and the MBR-RO process}
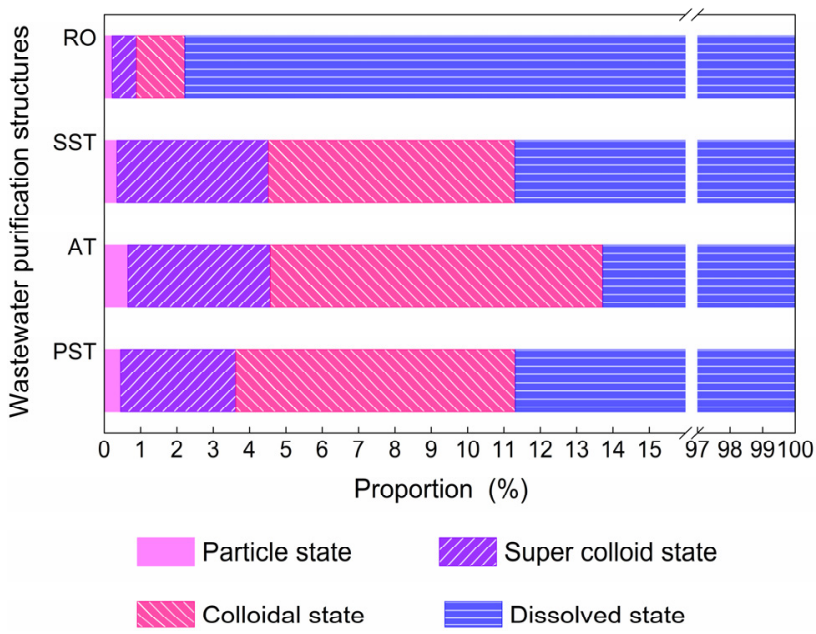

Fig. 4. PSD based COD occurrence characteristics of samples from the primary sedimentation tank (PST), the aerobic pool (AT), the secondary sedimentation tank (SST) and the MBR$\mathrm{RO}(\mathrm{RO})$ process. 
The relationship among four forms of COD in the primary sedimentation tank, aerobic tank, secondary sedimentation tank, and reverse osmosis-treated concentrated effluent was consistent(Fig. 4): soluble > colloidal $>$ supra colloidal $>$ settleable.

It can be revealed from the Fig. 4 that most COD collected from the primary sedimentation tank, the aerobic pool, the secondary sedimentation tank, the reverse osmosis external drainage after the MBR-RO process existed were in the dissolved state, accounting for $88.69 \%$, $86.28 \%, 88.70 \%$ and $97.78 \%$ of the whole organic matters, respectively. Almost no particle form COD was detected from all the four processes $($ all $<1 \%$ ).

\subsection{Variation of the particulate, super colloid, colloidal and dissolved COD content along with the water purification process}

As can be revealed from Fig. 5(a), the particulate COD appeared almost exclusively in the raw water, that was, in the conditioning tank; Only a small amount appeared in the primary sedimentation tank and the aerobic tank, and almost no existed in secondary sedimentation tank and reverse osmosis external drainage. By calculating the difference value of particulate COD between the raw wastewater and the PST, it could be aware that the PST removed most of the particulate COD with a removal rate of approximately $87.31 \%$. Considering the minimum limit of determination of the COD determination method, the
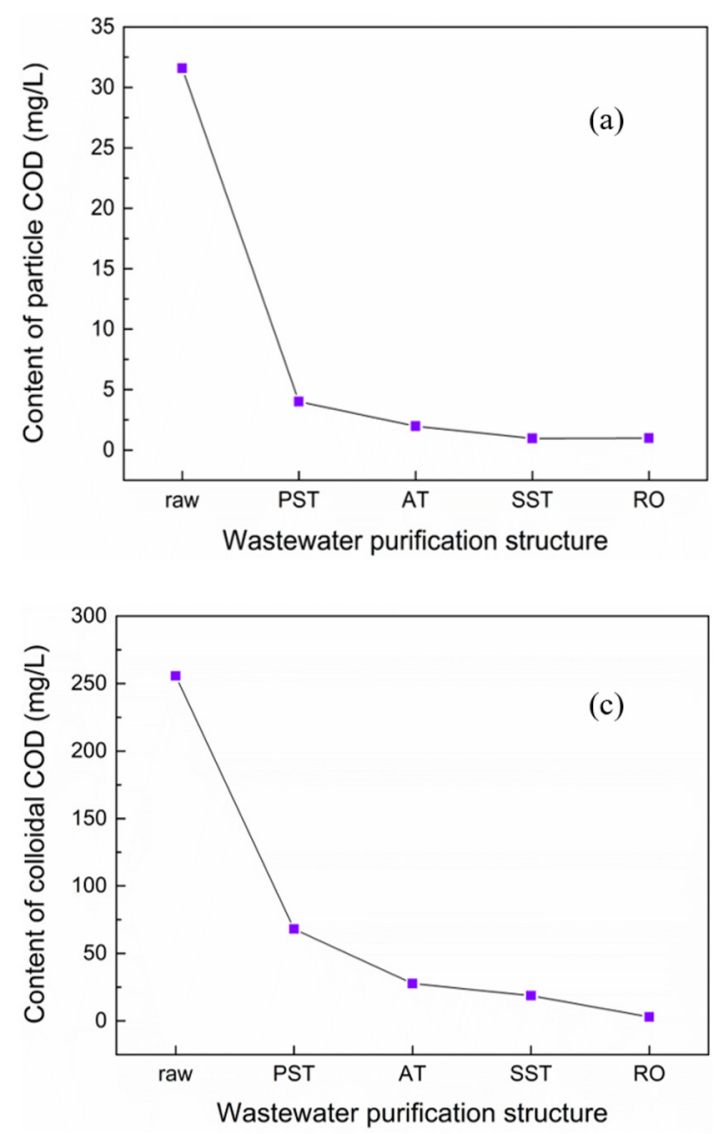

potassium dichromate method, the concentration of COD in the aerobic tank, the secondary sedimentation tank and the MBR-RO process was particularly low and could be ignored, which plays a positive role in the protection of the medium water reuse treatment membrane.

It can be seen from Fig. 5(b) that COD in the form of super colloids decreased very rapidly from $520.71 \mathrm{mg} / \mathrm{L}$ of raw water to $28.028 \mathrm{mg} / \mathrm{L}$ of primary sedimentation tank and reached a removal rate of $94.62 \%$, indicating that a large amount of super colloid COD was adsorbed into the sludge in the primary sedimentation tank. The concentration of super colloids COD in the aerobic tank was lower than the minimum limit concentration of the method. Therefore, the super colloids COD was almost completely treated by the aerobic tank and leaving nearly no super colloids COD existed the effluent of the secondary settling tank and the effluent concentrated water of the MBR-RO process, which is also beneficial to the protection of the membrane during the process of water reuse.

Also can be revealed from Fig. 5(c) that the colloidal COD changed from $255.621 \mathrm{mg} / \mathrm{L}$ of raw water to 68.668 $\mathrm{mg} / \mathrm{L}$ of the primary settling tank, and then changed to $27.668 \mathrm{mg} / \mathrm{L}$ of the aerobic tank, and finally changed to $18.677 \mathrm{mg} / \mathrm{L}$ of the secondary settling tank, the removal rates of COD in each treatment tank were $73.14 \%, 16.04 \%$ and $3.52 \%$, respectively. The colloidal COD in the external drainage treated by the MBR-RO process was $2.961 \mathrm{mg} / \mathrm{L}$, which was lower than the minimum limit of the determination limit of the method. Therefore, the
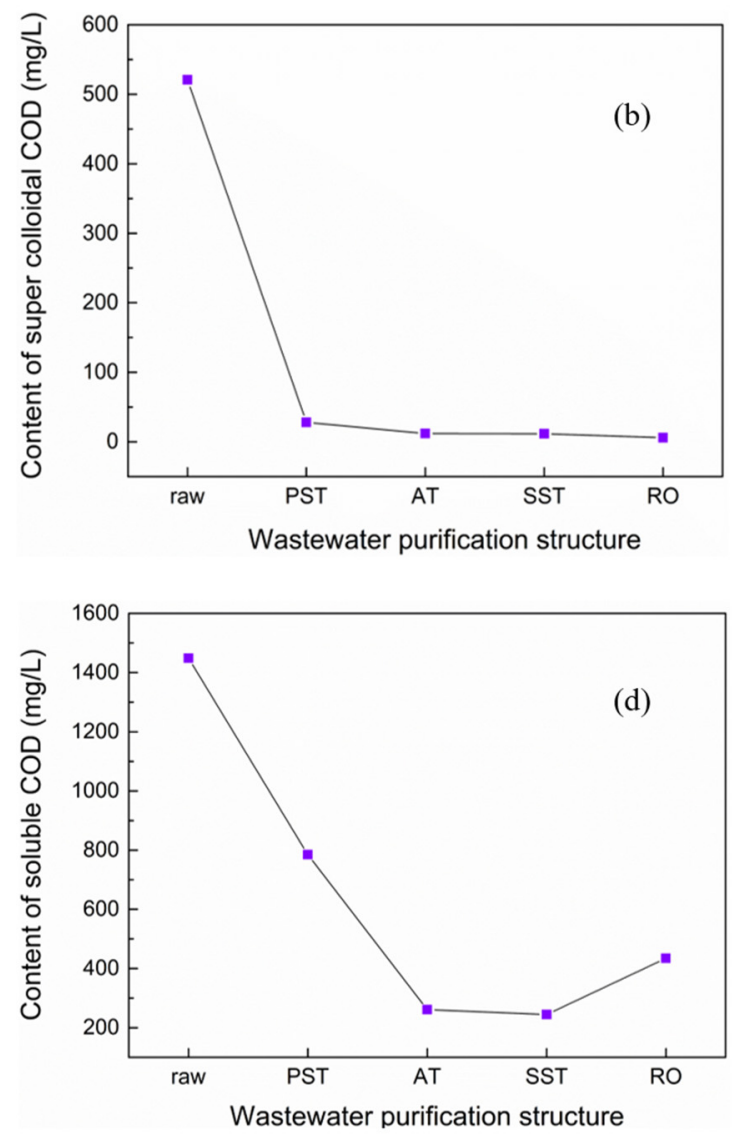

Fig. 5. Variation of particle(a), super colloidal(b), colloidal(c) and soluble(d) COD concentrations along with the primary sedimentation tank (PST), the aerobic pool (AT), the secondary sedimentation tank (SST) and the MBR-RO (RO) process. 
MBR-RO process removed all the colloidal COD remaining and there was almost no colloidal COD in the outer drainage. The concentration of the colloidal COD in the supernatant of the secondary sedimentation tank was $18.677 \mathrm{mg} / \mathrm{L}$, which made the concentration of the colloidal COD entering the MBR-RO process very low and was beneficial to alleviate the problem of membrane clogging in the process. The mixed wastewater of the secondary settling tank effluent and the MBR-RO process external drainage was discharged to the next sewage station.

For the dissolved form COD(Fig. 5(d)), the content changed from $1448.521 \mathrm{mg} / \mathrm{L}$ of raw water to 784.785 $\mathrm{mg} / \mathrm{L}$ of the primary settling tank, then changed to 260.87 $\mathrm{mg} / \mathrm{L}$ of the aerobic tank, and finally changed to 244.358 $\mathrm{mg} / \mathrm{L}$ of the secondary settling tank, the removal rates of COD by the above process were $45.82 \%, 36.17 \%$ and $1.14 \%$, respectively. The primary settling tank had a high removal ability of the dissolved COD, followed by the aerobic tank, and the secondary settling tank had the lowest removal capacity for $\mathrm{COD}<0.22 \mu \mathrm{m}$. The COD in the external drainage treated by the MBR-RO process was $434.268 \mathrm{mg} / \mathrm{L}$, which was 1.8 times that of the secondary settling tank, while the concentration of total COD in the water reused in the workshop was lower than 20 $\mathrm{mg} / \mathrm{LCOD}$. Therefore, the dissolved COD was mainly removed in the primary sedimentation tank and the aerobic tank, and the total removal rate of soluble COD was $83.13 \%$.

\section{Conclusion}

(1) In the dyeing wastewater, the occurrence characteristic of COD could be expressed as: soluble $>$ supra colloidal $>$ colloidal $>$ settleable. However, for protein, the supra colloidal was dominant, followed by the soluble. The feature of the polysaccharide was consistent with COD's. In the wastewater, $29.66 \%$ of COD could be attributed to proteins and $3.45 \%$ of the COD could be attributed to polysaccharides.

(2) The relationship among the forms of COD in the primary sedimentation tank, aerobic tank, secondary sedimentation tank, and reverse osmosis-treated concentrated effluent was consistent, that was soluble $>$ colloidal $>$ supra colloidal $>$ settleable.

(3) In the primary sedimentation tank, the settleable COD was almost completely removed. In the aerobic tank, the residual super colloidal COD was not much. After MBR-RO treatment, the COD in the reverse osmosis concentrated water was almost dissolved and only a little presented in other forms.

This work was supported by the National Key R\&D Program of China (No. 2018YFD1100503), the National Natural Science Foundation of China (No. 21676205), the National Science Fund for Distinguished Young Scholars (No. 51625804) and the Fundamental Research Funds for the Central Universities (No. 22120190012, 22120190054).

\section{References}

1. R. Wang, X. Jin, Z.Y. Wang, et al, Bioresour. Technol., 247, 1233-1241 (2017)

2. K. Vikrant, B.S. Giri, N. Raza, et al, Bioresour. Technol., 253, 355-367 (2018)

3. H. Ma, S.Y. Pu, Y.Q. Hou, et al, Chem. Eng. J., 345, 556-565 (2018)

4. H.F. Wu, S.H. Wang, J. Hazard. Mater., 243, 86-94 (2012)

5. J.D. Wang, T. Zhang, Y. Mei, et al, Chemosphere, 201, 621-626 (2018)

6. T. Salinas, I. Durruty, L. Arciniegas, et al, J. Environ. Manage., 218, 562-568 (2018)

7. S. Šostar-Turk, M. Simonič, I. Petrinić, Dyes Pigments, 64,147-152 (2005)

8. Ö. Karahan, S. Dogruel, E. Dulekgurgen, et al, Water Res., 42,1083-1092 (2008)

9. K. T. Ravndal, E. Opsahl, A. Bagi, et al, Water Res., 131, 151-160 (2018)

10. M.H. Huang, Y.M. Li, G.W. Gu, Desalination, 262, 36-42 (2010)

11. E. Dulekgurgen, S. Doğruel, Ö. Karahan, et al, Water Res., 40, 273-282 (2006)

12. X.Q. Jia, D.Y. Jin, C. Li, et al, Chin. J. Chem. Eng., 27, 444-451 (2019)

13. C. Sophonsiri, E. Morgenroth, Chemosphere, 55, 691-703 (2004)

14. B.W. Zhao, J.Z. Li, S.Y. Leu, Bioresour. Technol., 173, 384-391 (2014)

15. O. H. Lowry, N. J. Rosebrough, A. L. Farr, et al, J. Biol. Chem., 193, 265-275 (1951)

16. Y.B. Li, X. Wang, J.X. Liu, (in Chinese), Environ. Chem., 34, 2153-2161 (2015)

17. V. P. Kasperchik, A. L. Yaskevich, A. V. Bil' Dyukevich, Petrol. Chem+., 52, 545-556 (2012)

18. J. Mo, J. E. Hwang, J. Jegal, et al, Dyes Pigments, 72, 240-245 (2007) 